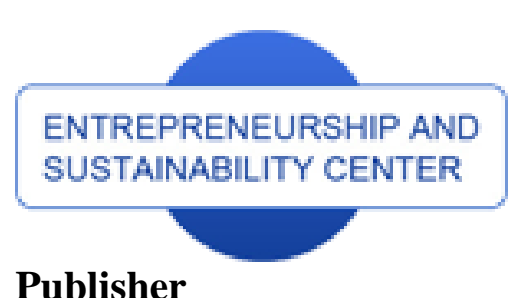

Publisher

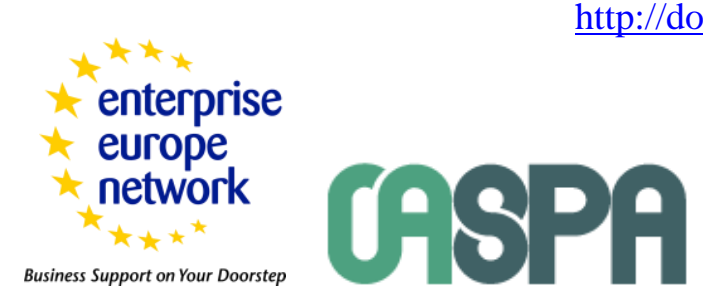

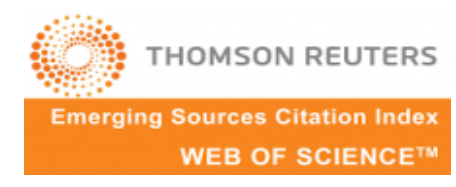

\title{
PERFORMANCE IMPLICATIONS OF ENTREPRENEURIAL ORIENTATION AT PUBLIC RESEARCH AND TECHNOLOGY INSTITUTIONS
}

\author{
Ali Khanagha ${ }^{1}$, Ali Mobini Dehkordi², Mohammad Reza Zali ${ }^{3}$, S. Reza Hejazi ${ }^{4}$ \\ ${ }^{1,2,3,4}$ Faculty of Entrepreneurship, University of Tehran, Tehran, Iran \\ E-mails: ${ }^{1}$ akhanagha@ut.ac.ir (Corresponding Author); ${ }^{2}$ mobini@ut.ac.ir; ${ }^{3}$ mrzali@ut.ac.ir; ${ }^{4}$ ehejazi@ut.ac.ir
}

Received 20 February 2017; accepted 10 May 2017

\begin{abstract}
This paper presents the results of a study on the Performance implications of Entrepreneurial Orientation (EO) at fifteen research centers within three public research and technology institutions (RTIs) in energy industry of Iran. Considering the sensitivity of EO construct to specific contexts, we initially developed a new scale to measure the EO of research centers; and then, investigated its consequences. Different latent interaction and multiple regression techniques were employed to investigate the effects of EO on performance indices of research centers from universalistic and contingency perspectives. It was concluded that EO has the strongest positive effect on financial performance of research centers, when they are dealing with unfavorable environmental conditions.
\end{abstract}

Keywords: Entrepreneurial Orientation, Public RTIs, Contingency/Situational Approach, Academic Entrepreneurship

Reference to this paper should be made as follows: Khanagha, A.; Dehkordi, A. M.; Zali, M. R.; Hejazi, S. R. 2017. Performance implications of entrepreneurial orientation at public research and technology institutions Entrepreneurship and Sustainability Issues 4(4): 601-610. http://dx.doi.org/10.9770/jesi.2017.4.4(15)

JEL Classifications: O32, L26, O31

\section{Introduction}

The essential role of knowledge in economic development of societies, especially in developing countries, has brought different types of academic and knowledge-based entrepreneurship into the attention. Nowadays, the authorities expect Universities and Public Research \& Technology Institutions (RTIs) to contribute in development of country by commercializing the results of publicly funded research. Therefore, RTIs are being encouraged to be more entrepreneurial, requiring inevitable changes in their governance structure (Todorovic et al., 2011). Despite the fact that everybody expects RTIs to be more entrepreneurial, very little is known about the appropriate strategies to achieve this objective; and the consequences thereafter.

In this study, we have utilized the renowned and widely-used construct of Entrepreneurial Orientation (EO) from corporate entrepreneurship to shed some light on benefits and consequences of being entrepreneurial at RTIs. By employing a mixed explorative research design, we first developed a contextualized variant of EO scale to measure the EO of 15 research centers within 3 public RTIs in Iran's energy industry. Later on, the predictive ability of this scale against the performance indices of research centers was deliberated from universalistic and 
contingency perspectives, considering different organizational and environmental factors that moderate the relationship.

\section{Literature Review}

The concept of Entrepreneurial Orientation (EO) is one of the widely used constructs in corporate entrepreneurship literature. Since its introduction to the scholarly community by Miller (1983), and subsequent development of its original measurement scale by Covin and Slevin (1989), this construct/scale has been used in many empirical studies by numerous scholars. According to the literature, the concept of EO is significant because it fills an important gap in entrepreneurship literature by denoting the characteristics of an entrepreneurial firm (Covin and Lumpkin, 2011), in three dimensions of "Proactiveness", "Risk taking", and "Innovation". A decade after its introduction, Lumpkin and Dess (1996) augmented the scale with two dimensions of "Competitive Aggressiveness" and "Autonomy".

EO encompasses entrepreneurial strategy-making policies, practices and processes aimed at developing opportunities for the organization (Muchiri and McMurray, 2015); and some authors have presented EO consisting of processes, structures, or behaviors that can be described as aggressive, innovative, proactive, risk taking, or autonomy seeking. In a nutshell, EO is a behavioral construct which could be viewed as a set of policies (practices), processes (procedures) as well as activities (behaviors) which form the basis of an organization's engagement in entrepreneurial activities. For the purpose of this research, EO construct and its relationship with Performance have some subtle properties which had to be noted while planning and performing the research, and henceforward we will briefly mention these significant issues:

2.1. Organizational Context: It is vital to memo that EO scale has been developed and used for private firms; and thus, its measurement scales have limited applicability in other organizational contexts. It is almost intuitive that meaning of being "Entrepreneurially Oriented" must be different within public or non-profit sectors, due to inevitable differences in their objectives, structure, and governance structure (Todorovic et al., 2011; Zahra et al., 2014). As an instance, a specific unidimensional measurement scale for university departments has been developed by Todorovic et al. (2011). This contemplation led us to the idea that for the purpose of measuring the EO of research centers within public RTIs, we need to first develop a context-specific measurement scale. In our study, we first developed a new measurement scale, measured by 25 items, demonstrating the propensity of research centers to engage in academic entrepreneurship; which proved to have a relatively strong positive effect on their financial performance.

2.2. Relationship with Performance: While many empirical studies have concluded that $\mathrm{EO}$ has a positive impact on performance of the firms (Rauch et al., 2009) especially in hostile environments (Covin and Slevin, 1989), there has been a long debate on whether EO is always an appropriate strategic orientation? Initially, the EO studies were founded on the universal effect approach, assuming that EO is universally beneficial. Later on, based on premises of Contingency theory, EO literature discussed many variables moderating the EOperformance relationship (Linton, 2016; García-Villaverde et al., 2013; De Clercq et al., 2010). Empirical research has found that the effect of EO on performance varies in dissimilar environments and internal settings, highlighting the importance of a contingent approach (two-way interaction). Moreover, it is crucial to recognize the multidimensional nature of the Performance construct. Employing Entrepreneurial strategy and EO may, at times, lead to favorable outcomes on one performance dimension and unfavorable outcomes on a different performance dimension. Therefore, it is essential to memo that the conceptual argument of the EO-performance 
relationship focuses mainly on financial aspects of performance and the relationship between the EO construct and nonfinancial goals is less straightforward and expected to be weak, due to tenuous nature of the relationship.

2.3. Entrepreneurship at Public RTIs: Research and Technology Institutions (RTIs), and the specialized Research Centers therein, should be considered as hybrid organizations along two dimensions. They often occupy an intermediary position between public and private organizations when it comes to outputs, governance, ownership, and other issues. In an ideal world, the hybrid nature of research Institutions/centers can create opportunities for combinations of academic work and practical problem-solving (Gulbrandsen, 2011). As an essential part of national innovation system, RITs are expected to involve in knowledge-intensive entrepreneurship, and consequently, play a role in innovation, transformation of industrial system and economic growth. In the broad sense, knowledge-intensive entrepreneurship may take place in various ways: through the foundation of new firms, or through the display of entrepreneurial spirit within existing firms, or through the actions within public research organizations such as universities or RTIs. The latter form is commonly known as Academic Entrepreneurship, and could be defined as the involvement of academic scientists and organizations in commercially relevant activities in different forms, including industry-university collaborations, university-based venture funds, university-based incubator firms, start-ups by academics, and double appointments of faculty members in firms and academic departments.

\section{Conceptual framework \& Hypotheses}

The conceptual framework of study has been depicted in Figure 1. It is a contextualized version of the proposed framework by Lumpkin and Dess (1996) which relates EO of organization to its Performance. Consistent with EO literature, the following hypotheses were developed for investigation:

$\mathrm{H}_{1}$ : EO has a positive effect on financial performance of research centers

$\mathrm{H}_{2}$ : EO has a positive effect (weaker than $\mathrm{H}_{1}$ ) on non-financial indices of research centers

$\mathrm{H}_{3}$ : The relationship between EO and financial performance is moderated by RTI policies. Favorable policies of RTI regarding entrepreneurship, strengthens the relationship

$\mathrm{H}_{4}$ : The relationship between EO and financial performance is moderated by environmental factors. Favorable environmental conditions dampen the positive relationship between EO and financial performance.

$\mathrm{H}_{5}$ : The relationship between EO and financial performance is moderated by internal factors. Favorable internal conditions strengthen the positive relationship between $\mathrm{EO}$ and financial performance. 
Figure 1: Conceptual framework of research

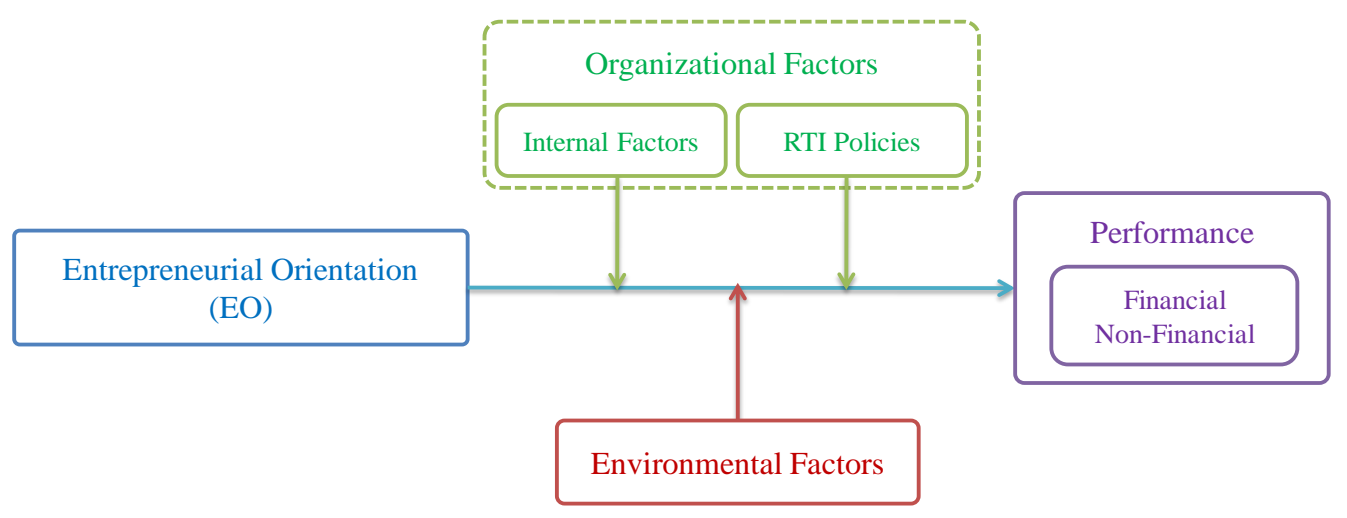

3.1. Operationalization of Constructs: Historically, the construct of EO and its related measurement scales in the corporate entrepreneurship literature have been developed and validated for private firms (Covin and Slevin, 1989; Lumpkin and Dess, 1996). In recent years, several scholars have questioned the applicability of EO scales in organizational contexts other than private firms, such as governmental and non-profit organizations, and thus, it has been suggested that contextualized variations of EO scale must be developed to be used in specific organizations (Todorovic et al., 2005; Zahra et al., 2014). With this premise, we employed exploratory sequential (Qualitative - Quantitative) design (Creswell and Clark, 2007), to first develop an scale to measure EO within our specific context, as well as other constructs within our conceptual framework.

Consistent with scale development literature by (Hinkin, 1995; Worthington and Whittaker, 2006; Stratman and Roth, 2002), Phase 1 (qualitative) was designed to generate the items related to constructs in the conceptual framework. We performed semi-organized extensive interviews with top and middle managers of 15 research centers within three RTIs, using an interview protocol which was the results of a thorough review of EO literature. The interviews were recorded and then transcribed to be used in open and axial coding (theme analysis).

After generating the potential items for each construct, and for reducing the number of potential items (Item purification), we initially performed a pilot survey in two research centers; and by help of a focus group and factor analysis, the final instrument was developed in which 25 items were meant to measure the EO of research centers. Furthermore, a total of 18 items were selected (based on the discrimination they brought to the instrument) to represent other constructs - environmental factors (6), internal factors (5), and RTI policies (7) - in the final instrument. By adding four questions to assess the financial and scientific performance of research centers (monetary performance, granted patents, published papers and published books), the final questionnaire was formed with 47 questions in likert scale for the final survey.

The organizational survey was performed in 15 research centers of three RTIs in Energy Industry of Iran. Equal number of 23 questionnaires was distributed among the target population of each research center (middle managers); which resulted in 181 responses (representative of about $\% 51$ of the target population). The gathered data was then used to investigate the research hypotheses. 


\section{Performance Implications}

In this section, we utilized Structural Equation Modeling (SEM) \& Multiple Regression techniques to investigate the EO-performance relationship from various perspectives, by examining the 6 research hypotheses as described before. We used IBM AMOS $\mathrm{v}_{24}$ to build measurement models of all constructs within our conceptual framework (Figure 1), and then investigated reliability, convergent validity, \& discriminant validity of constructs (Table 1). It was concluded that measurement models are in good fit with data (181 cases), the constructs are reliable, and validity criteria is fulfilled.

Table 1: Reliability, Convergent validity and Discriminant validity analysis

\begin{tabular}{|c|c|c|c|c|c|c|c|}
\hline Reliability & \multicolumn{7}{|c|}{ Convergent \& Discriminant Validity } \\
\hline$\alpha>0.7$ & Constructs & $\mathrm{CR}$ & AVE & MSV & Int. Factors & EO & Env. Factors \\
\hline 0.917 & Int. Factors & 0.963 & 0.838 & 0.187 & 0.915 & & \\
\hline 0.961 & EO & 0.894 & 0.678 & 0.340 & 0.432 & 0.823 & \\
\hline 0.945 & Env. Factors & 0.940 & 0.727 & 0.340 & 0.320 & 0.583 & 0.853 \\
\hline
\end{tabular}

4.1. Universalistic Perspective: This perspective simply assumes that EO is always beneficial, mainly for financial performance. In order to examine the $\mathrm{H}_{1}$ and $\mathrm{H}_{2}$ hypotheses, we fitted five structural models to dataset with EO as independent variable (predictor) and different performance indices as dependent variable. Table 2 reports the results, which indicate that EO has a substantial positive relationship with financial performance $\left(\mathrm{R}^{2}=\% 39\right)$, and the relationship is weaker for other performance indices.

Accordingly, it can be concluded that $\mathrm{H}_{1}$ and $\mathrm{H}_{2}$ are correct. It is remarkable that the strongest relationship among non-financial indices is for patents, showing that EO is able to explain $\% 11$ of variance in patenting activates by a research center. This is due to a relatively close relationship between patenting and technology commercialization, which is consistent with the findings of Todorovic et al. (2011). Furthermore, the goodness of fit indices for five structural models were investigated and it was concluded that they are all within acceptable range and the relationships are statistically significant, except for $\mathrm{Sp}_{3}$ (books) denoting that there is no significant relationship between EO and publication of books.

Table 2: SEM regression results on different independent variables

\begin{tabular}{c|c:c}
\hline Structural Model & $\begin{array}{c}\text { Index } \\
\text { Standardized regression } \\
\text { weight }^{\text {p-value }}\end{array}$ & $\begin{array}{c}\text { Variance explained } \\
\left(\mathrm{R}^{2}\right)\end{array}$ \\
\hline $\mathrm{EO} \rightarrow \mathrm{Fp}$ (Financial Performance) & $0.63^{* * *}$ & $\% 39$ \\
\hline $\mathrm{EO} \rightarrow \mathrm{Sp}_{1}$ (Research Papers) & $0.24^{* *}$ & $\% 11$ \\
\hline $\mathrm{EO} \rightarrow \mathrm{Sp}_{2}$ (Patents) & $0.33^{* * *}$ & $\% 1$ \\
\hline $\mathrm{EO} \rightarrow \mathrm{Sp}_{3}$ (Published Books) & $0.10^{\mathrm{p}=0.194}$ & $\% 8$
\end{tabular}


4.2. Contingency Perspective: The contingency approach simply acknowledges the fact that the effect of EO on financial performance is under the influence of other issues as well. Corresponding to our conceptual framework, we separately investigated the moderating effect of three constructs (RTI polices, Environmental factors, and Internal factors) on EO-financial performance relationship to examine hypotheses $\mathrm{H}_{3}, \mathrm{H}_{4}$, and $\mathrm{H}_{5}$ respectively:

4.2.1. $R T I$ policies $\left(\boldsymbol{H}_{3}\right)$ : In our survey, 7 items were intended to measure this construct which belongs to a higher level of analysis. For all research centers within the same RTI, this construct plays the role of a constant (i.e. control variable). Thus, the variations in this construct are meant to differentiate RTIs in terms of their encouraging policies regarding academic entrepreneurship. Noting that our sample is drawn from three different RTIs, we used multi-group moderation technique to examine $\mathrm{H}_{3}$ hypothesis. By interpreting "RTI policies" as a categorical variable, we calculated the un-weighted mean of seven related items to generate a score for each RTI. A multi-group moderation analysis was then conducted to see the chi-square difference in fully constrained and un-constrained models. For one of RTIs with a very low number of samples, the EO-performance relationship was not significant, and for other two RTIs, the results have been reported in Table 3.

As the chi-square difference between the two groups is more than the calculated threshold (4.61 for $\% 90$ confidence), it can be concluded that favorable RTI polices will strengthen the positive effect of EO on financial performance of research centers, as evident by the differences between RTIs I \& II in the Table 5 (higher RTI score is consistent with better performance and stronger relationship); therefore, we can conclude that $\mathrm{H}_{3}$ is approved (with \%90 confidence).

Table 3: Multi-group Moderation analysis results (chi-square difference $=4.9$ )

\begin{tabular}{|c|c|c|c|c|}
\hline RTI & Standardized regression weight ${ }^{p \text {-value }}$ & Variance explained $\left(\mathbf{R}^{2}\right)$ & RTI Policy (Score) & Performance (Score) \\
\hline $\bar{I}$ & $0.596^{\text {**** }}$ & $\% 35$ & 1.35 & 2.51 \\
\hline II & $0.414^{* *}$ & $\% 17$ & 1.15 & 2.44 \\
\hline
\end{tabular}

4.2.2. Environmental and Internal factors $\left(\boldsymbol{H}_{4} \& \boldsymbol{H}_{5}\right)$ : The "Environmental Factors" construct represents the influencing factors from the research center's close environment which is beyond the control of both RTI and research center. In order to operationalize this construct, the related codes were separated in interviews and by a frequency-based approach, six items with the highest frequency were selected to be included in instrument in conceptual categories of "Industry Characteristics" and "Environment Munificence" which are both consistent with the suggestions of EO literature (Covin and Lumpkin, 2011). The "Internal factors" construct corresponds to some internal organizational characteristics which influence all activities within the research center (including entrepreneurial activities). A number of these characteristics are the inevitable results of some historic pathway, social values, etc. Although these factors are not completely under control of the management, it does make sense to assume that the management policies can influence these factors (at least in mid-term); and consequently, providing a better environment for entrepreneurial activities. Same as the environmental factors, in order to operationalize this construct, the related codes were separated in interviews and by a frequency-based approach (inductive), and five items with the highest frequency (mentioned by more than 10 interviewees) were selected to be included in the final instrument in two conceptual categories of "Management Style" and "Organizational Culture" which are both consistent with the suggestions of EO literature (Leyerer, 2012).

In order to carefully examine $\mathrm{H}_{4} \& \mathrm{H}_{5}$, we decided to employ a combination of multiple regression techniques and SEM. In multiple-regression, an interaction term is expected to be uncorrelated with the predictor variables to avoid the problem of collinearity. In reality, the product term always has some degree of correlation with predictor variables which leads to problems of instability of estimated regression weights. To overcome this 
challenge, we employed prior mean-centering of variables (Hayes, 2013), and a two step technique called residual-centering has been proposed to ensure the orthogonality of the product term and its constituents (Little et al., 2007). Although multiple regression techniques are vastly popular and rather easy to implement, we decided to additionally utilize a latent-variable interaction technique with SEM, known as Moderated Structural Equation Modeling (MSEM), to enhance the robustness of the results. Among many available MSEM methods, we used a method proposed and enhanced by Ping (1995 - 2011) in which only one interaction term is being calculated in a two-stage process to be included in the MSEM. The main advantage of Ping method is that it does not increase the model's degrees of freedom. Details of this technique have been described at (Foguet et al., 2008; Convey et al., 2015; Ping, 1995; Ping, 2001). Tables 4 and 5 have reported the results of applying three techniques on data with different moderators. As evident in Tables 4 and 5, it can be concluded that:

$\stackrel{\leftrightarrow}{\rightarrow}$ Environmental factors negatively moderates the EO-financial performance relationship (i.e. damps the relationship by reducing the slope). The results of three techniques are similar; all indicating a statistically significant negative moderating effect on relationship. Adding the moderator and interaction clearly have increased the predictive capability of model and the full model is able to explain $\% 45 \sim \% 48$ of variance in financial performance, of which, $\% 2.6 \sim \% 3$ is on behalf of the interaction term. This last observation is of particular importance since the interaction term is proved to be able to explain a unique and statistically significant share of variance. In conclusion, it is evident that EO effect on financial performance of research centers is contingent upon different environmental conditions, and interaction of these variables has a meaningful effect of the dependent variable. The direction of this effect has been depicted in Figure 2 by plotting the conditional effect of EO on financial performance in different values of moderator. Obviously, higher level of moderator dampens the relationship and the maximum effect of EO on financial performance is within lower values of moderator (i.e. bad environmental conditions). Consequently, the results approve $\mathrm{H}_{4}$ in the context of study. Moreover, we employed the Johnson-Neyman technique (Hayes, 2013) to identify the significance range of moderating effect. It was showed that significance region covers \% 87.7 of moderator values; and, the moderation is NOT significant at highest levels of Environmental factors (\% 12.3). It can be concluded that in very favorable environmental conditions, the effect of EO on financial performance will probably vanish.

$\leftrightarrow$ Internal factors may positively moderate the EO-financial performance relationship (i.e. strengthen the relationship by reducing the slope). In all three techniques, the moderating effect is NOT statistically significant, although the direction of effect is positive. Adding the moderator and interaction to model enhances the predictive capability up to $55 \sim 59$ percent, but the variance explained by the interaction term is less than 1 percent and statistically insignificant. For conceptual purposes, The direction of this insignificant effect has been depicted in Figure 2 by plotting the conditional effect of EO on financial performance in different values of moderator, implying that the better internal conditions, the stronger the relationship between EO and financial performance. Consequently, the results can NOT approve the hypothesis $\mathrm{H}_{5}$.

Table 4: Un-standardized Regression Coefficients for different predictors (A: Environmental factors, B: Internal factors)

\begin{tabular}{c|c|c|c|c|c|c}
\hline \multirow{2}{*}{ Method } & \multicolumn{2}{|c|}{ Ping MSEM } & \multicolumn{2}{c|}{ Residual Centering } & \multicolumn{2}{c}{ Mean-Centering } \\
\cline { 2 - 7 } Predictors & A & B & A & B & A & B \\
\hline Independent Variable (EO) & $0.66^{* * *}$ & $0.57^{* * *}$ & $0.59^{* * *}$ & $0.55^{* * *}$ & $0.61^{* * *}$ & $0.56^{* * *}$ \\
\hline Moderator (A or B) & $0.24^{* * *}$ & $0.51^{* * *}$ & $0.34^{* * *}$ & $0.52^{* * *}$ & $0.30^{* * *}$ & $0.53^{* * *}$ \\
\hline Interaction (EO $\times$ Moderator) & $-0.18^{* * *}$ & $0.07^{\mathrm{p}=0.167}$ & $-0.23^{* * *}$ & $0.089^{\mathrm{p}=0.186}$ & $-0.23^{* *}$ & $0.088^{\mathrm{p}=0.143}$
\end{tabular}


ENTREPRENEURSHIP AND SUSTAINABILITY ISSUES

ISSN 2345-0282 (online) http://jssidoi.org/jesi/

2017 Volume 4 Number 4 (June)

http://doi.org/10.9770/jesi.2017.4.4(15)

Table 5: Variance Explained $\left(\mathrm{R}^{2}\right)$ for different predictors (A: Environmental factors, B: Internal factors)

\begin{tabular}{c|c|c|c|c|c|c}
\hline \multirow{2}{*}{ Method } & \multicolumn{2}{|c|}{ Ping MSEM } & \multicolumn{2}{c|}{ Residual Centering } & \multicolumn{2}{c}{ Mean-Centering } \\
\cline { 2 - 7 } & A & B & A & B & A & B \\
\hline Independent Variable (EO) & $0.39^{* * *}$ & $0.39^{* * *}$ & $0.34^{* * *}$ & $0.34^{* * *}$ & $0.34^{* * *}$ & $0.34^{* * *}$ \\
\hline Moderator (A \& B) & $0.31^{* * *}$ & $0.44^{* * *}$ & $0.30^{* * *}$ & $0.42^{* * *}$ & $0.30^{* * *}$ & $0.42^{* * *}$ \\
\hline EO, Moderator & $0.45^{* * *}$ & $0.58^{* * *}$ & $0.42^{* * *}$ & $0.55^{* * *}$ & $0.42^{* * *}$ & $0.55^{* * *}$ \\
\hline EO, Moderator, Interaction & $0.48^{* * *}$ & $0.59^{* * *}$ & $0.45^{* * *}$ & $0.56^{* * *}$ & $0.45^{* * *}$ & $0.56^{* * *}$ \\
\hline$\Delta \boldsymbol{R}^{2}$ for Interaction & $0.03^{* * *}$ & $0.009^{\mathrm{p}=0.167}$ & $0.026^{* * *}$ & $0.004^{\mathrm{p}=0.186}$ & $0.026^{* *}$ & $0.004^{\mathrm{p}=0.143}$
\end{tabular}

Figure 2: Graphical depiction of moderating effect on EO-performance relationship Left: Environmental factors (significant), Right: Internal factors (insignificant)
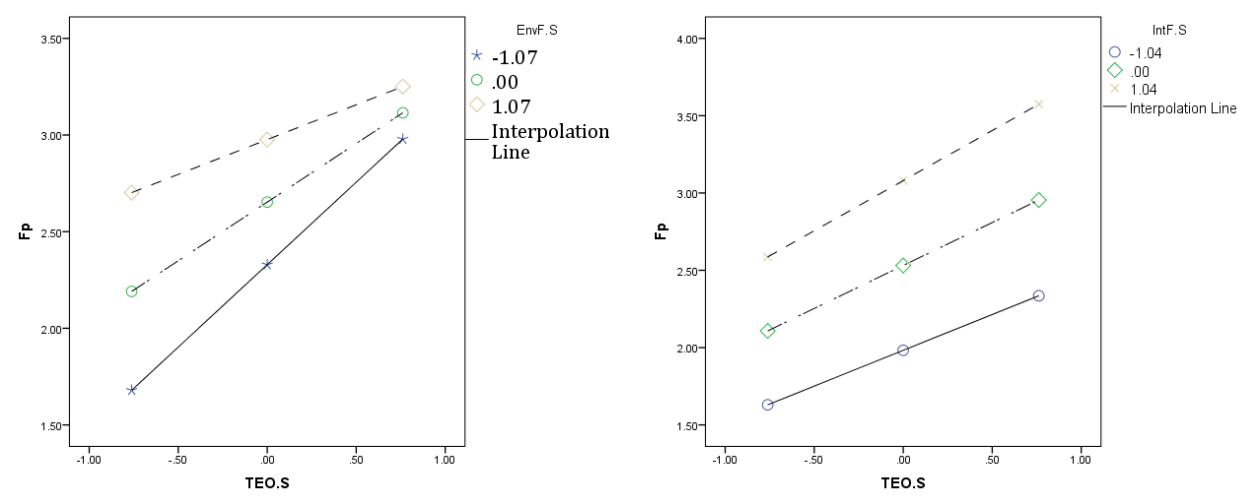

\section{Discussion}

In this research, by developing a contextualized variant of EO scale to measure the Entrepreneurial Orientation of public research centers, we used SEM and multiple-regression techniques to investigate the EO-Performance relationship by examining six research hypotheses. Regarding EO-Financial Performance relationship, while positive effect of "internal factors" does make sense, the negative effect of "environmental factors" seems to be odd, and needs some explanation. This phenomenon, which is in fit with previous empirical studies in EO literature (Wiklund and Shepherd, 2005; Covin and Slevin, 1989), could be described from both practical and theoretical points of view:

From practical perspective, the research center working in an environment so favorable, in which many opportunities are available to be exploited, does not need to employ an entrepreneurial strategy to get a project. When industry conditions are favorable for technological activities and environment munificence is at high levels, the ability to discover or create new opportunities is not of use, and research center (more or less) will benefit from the positive conditions. In such circumstances, the organization can improve its financial performance just by focusing on its internal conditions to increase the efficiency in opportunity exploitation. From theoretical viewpoint, we rely on resource-based theory of the firm which suggests that each organization is a unique bundle of resources, capabilities, and competencies; and the competitive advantage is the result of difference in this unique bundle. EO is a source of discrimination and competitive advantage, in the sense that high levels of EO enable the research center to discover or create new technological opportunities to be exploited. The point is, the EO-induced discrimination is of more importance in unfavorable environmental conditions; and thus, EO is a discrimination mechanism for harsh conditions, in which the industry (for any reason) is not eager for technological collaboration. 


\section{The International Journal}

ENTREPRENEURSHIP AND SUSTAINABILITY ISSUES

ISSN 2345-0282 (online) http://jssidoi.org/jesi/

2017 Volume 4 Number 4 (June)

http://doi.org/10.9770/jesi.2017.4.4(15)

\section{References:}

Convey E, Fu N and Alfes K. (2015) Demands or Resources? The Relationship Between HR Practices, Employee Engagement, and Emotional Exhaustion Within a Hybrid Model of Employment Relations. Human resource Management. http://dx.doi.org/10.1002/hrm.21691

Covin JG and Lumpkin GT. (2011) Entrepreneurial Orientation Theory and Research: Reflections on a Needed Construct. Entrepreneurship Theory and Practice (ET\&P), Special Issue on Entrepreneurial Orientation Volume 35: 855-872. http://dx.doi.org/10.1111/j.1540-6520.2011.00482.x

Covin JG and Slevin DP. (1989) Strategic management of small firms in hostile and benign environments. Strategic Management Journal 10: 75-87.(http://dx.doi.org/10.1002/smj.4250100107

Creswell JW and Clark VL. (2007) Designing and conducting mixed methods research: SAGE Publications Inc.

De Clercq D, Dimov D and Thongpapanl N. (2010) The moderating impact of internal social exchange processes on the entrepreneurial orientation-performance relationship. Journal of Business Venturing: 87-103. http://dx.doi.org/10.1016/j.jbusvent.2009.01.004

Foguet JMB, Coenders G and Saris WE. (2008) A Parsimonious Approach to Interaction Effects in Structural Equation Models: An Application to Consumer Behavior. Quality \& Quantity - International Journal of Methodology 42: 369-396.

García-Villaverde PM, Ruiz-Ortega MJ and Canales JI. (2013) Entrepreneurial orientation and the threat of imitation: The influence of upstream and downstream capabilities. European Management Journal 31: $263-277$. http://dx.doi.org/10.1016/j.emj.2012.11.006

Gulbrandsen M. (2011) Research institutes as hybrid organizations: central challenges to their legitimacy. Policy Sciences 44: 215-230. http://dx.doi.org/10.1007/s11077-011-9128-4

Hayes AF. (2013) Introduction to Mediation, Moderation, and Conditional Process Analysis, A Regression-Based Approach: The Guilford Press. http://dx.doi.org/10.1111/jedm.12050

Hinkin TR. (1995) A Review of Scale Development Practices in the Study of Organizations. Journal of Management 21: 967-988. https://doi.org/10.1177/014920639502100509

Leyerer PS. (2012) The Role Of Organizational Culture In Developing An Entrepreneurial Oriented Company. Master thesis, School of Economics and Management, Department of Business Administration.

Linton G. (2016) Entrepreneurial Orientation, Reflections from a contingency Prespetive, PhD Thesis, Örebro University , Sweden.

Little TD, Card NA and Bovaird JA. (2007) chapter 9: Structural Equation Modeling of Mediationand Moderation With Contextual Factors little. Modeling Contextual Effects in Longitudinal Studies. 207-230. http://dx.doi.org/10.4324/9780203936825

Lumpkin GT and Dess GG. (1996) Clarifying the Entrepreneurial Orientation Construct and Linking It to Performance. Academy of Management Review 21: 135-172. http://dx.doi.org/10.5465/AMR.1996.9602161568

Miller D. (1983) The correlates of entrepreneurship in three types of firms. Management Science 29: 770-792. https://doi.org/10.1287/mnsc.29.7.770

Muchiri M and McMurray A. (2015) Entrepreneurial orientation within small firms: a critical review of why leadership and contextual factors matter. Small Enterprise Research 22: 17-31. https://dx.doi.org/10.1080/13215906.2015.1017076

Ping RA. (1995) A Parsimonious Estimating Technique for Interaction and Quadratic Latent Variables. Journal of Marketing Research 32 : 336-347. http://dx.doi.org/10.2307/3151985

Ping RA. (2001) A parsimonious estimating technique for Interaction and quadratic latent variables (Revised version at: http://www.wright.edu/ robert.ping/research1.htm).

Rauch A, Wiklund J, Lumpkin GT, et al. (2009) Entrepreneurial Orientation and Business Performance: An Assessment of Past Research and Suggestions for the Future. Entrepreneurship Theory and Practice 33: 761-787. http://dx.doi.org/10.1111/j.1540$\underline{6520.2009 .00308 . x}$

Stratman JK and Roth AV. (2002) Enterprise Resource Planning (ERP) Competence Constructs: Two-Stage Multi-Item Scale Development and Validation. Decision Sciences 33: 601-628. http://dx.doi.org/10.1111/j.1540-5915.2002.tb01658.x

Todorovic WZ, McNaughton RB and Guild PD. (2005) Making university departments more entrepreneurial, The perspective from within. The International Journal of Entrepreneurship and Innovation 6: 115-122. https://doi.org/10.5367/0000000053966858 
The International Journal

ENTREPRENEURSHIP AND SUSTAINABILITY ISSUES

ISSN 2345-0282 (online) http://jssidoi.org/jesi/

2017 Volume 4 Number 4 (June)

http://doi.org/10.9770/jesi.2017.4.4(15)

Todorovic ZW, McNaughton R and Guild P. (2011) ENTRE-U: An Entrepreneurial Orientation Scale for universities. Technovation: 128137.(http://dx.doi.org/10.1016/j.technovation.2010.10.009

Wiklund J and Shepherd D. (2005) Entrepreneurial orientation and small business performance: a configurational approach. Journal of Business Venturing 20: 71-91. http://dx.doi.org/10.1016/j.jbusvent.2004.01.001

Worthington RL and Whittaker TA. (2006) Scale Development Research A Content Analysis and Recommendations for Best Practices. The Counseling Psychologist. https://doi.org/10.1177/0011000006288127

Zahra S, Wright M and Abdelgawad S. (2014) Contextualization and the advancement of entrepreneurship research. International Small Business Journal: 1-22. https://doi.org/10.1177/0266242613519807

Ali Khanagha is a PhD candidate at the Faculty of Entrepreneurship, University of Tehran. He holds B.Sc. and M.Sc. degrees in electrical engineering (Bioelectric major), and an MBA degree. He is currently the head of International Affairs department at Research Institute of Petroleum Industry (RIPI), the largest public research institution in Iran. His main topic of interest is technology and R\&D management. At present, Mr. Khanagha is working on his $\mathrm{PhD}$ thesis focused on developing a new measurement scale for Entrepreneurial Orientation (EO) at Public research \& technology institutions of Iran's energy sector, under supervision of Dr. Mobini.

ORCID ID: orcid.org/0000-0002-9667-3730
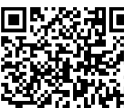

回证然

Register for an ORCID ID:

https://orcid.org/register

Copyright (C) 2017 by author(s) and VsI Entrepreneurship and Sustainability Center

This work is licensed under the Creative Commons Attribution International License (CC BY).

http://creativecommons.org/licenses/by/4.0/

cC) (7) Open Access 